\title{
Student Affairs and Hurricane Katrina: Contextual Perspectives from Five Institutions of Higher Education in New Orleans
}

\author{
Susan K. Gardner \\ Kristy Miller \\ Marco Barker \\ Jennifer Loftin \\ Marla Erwin \\ Kay Maurin
}

Fifteen student affairs administrators from five institutions of higher education in New Orleans were interviewed regarding their experiences immediately before and after Hurricane Katrina and how the crisis affected their work. Participants were chosen for their diversity among racial, gender, and institutional contexts. Analyses of the interviews resulted in four themes that describe the

Susan K. Gardner is an assistant professor of Higher Education at Louisiana State University (LSU) in Baton Rouge, Louisiana. Kristy Miller is the assistant director of the Campus Community Coalition for Change at LSU. Marco Barker is the assistant to vice provost for Equity, Diversity, and Community Outreach at LSU. Jennifer Loftin is the associate director for Strategic Initiatives in the Flores MBA program at LSU. Marla Jane Erwin is a doctoral candidate in Higher Education and instructor of Psychology at LSU. Kay Maurin is the director of Disability Services at Southeastern Louisiana University in Hammond, Louisiana. 
differences between how public versus private institutional cultures affected these administrators' responses and the decision making that occurred in the wake of the storm. These themes include (a) decision making, (b) communication, (c) resources and limitations, and (d) student affairs status. Implications for policy, practice, and research are included.

Hurricane Katrina hit the Gulf Coast of the United States on August 29, 2005. As the third strongest hurricane to make landfall in the U.S., Katrina ravaged much of the Mississippi and Louisiana coast lines. Among the cities most desperately affected by the hurricane was New Orleans, Louisiana. Causing over \$81 million in damages and killing over 1,800 people in New Orleans alone, Katrina was not only the costliest but also one of the deadliest natural disasters the United States has ever seen. While much of the damage was incurred as a result of the subsequent failure of the levee system in the city itself, the damage caused by the failing bureaucratic responses to the disaster as well as the lack of preparation for the disaster was immeasurable.

After Hurricane Katrina hit New Orleans, much changed. Where once homes stood, now there is wreckage. Where once streets ran, now there are gaping holes in the earth. And where once higher education flourished in its many forms, now there are institutions struggling to recover not only from the physical devastation ravaged upon them but also from the personal, emotional, and financial losses that have resulted. While media outlets such as The Chronicle of Higher Education diligently covered the effects of Hurricanes Katrina and Rita on the institutions of higher education throughout the Gulf Coast, the stories they told were those of the upper administration: the presidents, the chancellors, and the business officers (e.g., Cowen \& Wildes, 2006; Hoover, 2005; Mangan, 2005; Selingo, 2005, 2006). The media often reflected upon the struggles faced by these administrators, peppering their accounts with quotes by students and even faculty affected by the storms and the ensuing aftermath. What was not present in these accounts, however, were the voices of the frontline student affairs administrators who weathered the storms with the students who remained on their campuses, who risked their own lives to save others', and who rose above what were often inhuman conditions to bring 
their students back to their campuses and to sustain programs that took generations to build. In this paper we present the stories of 15 student affairs administrators at five institutions of higher education in New Orleans, relaying their tales of how Hurricane Katrina forever changed their work, their lives, and the way they view student affairs.

\section{The Context and Culture: A Conceptual Framework}

We began by asking the question, "How did Hurricane Katrina affect the work of student affairs administrators in New Orleans?" We sought to hear the voices of those individuals in student affairs who were present before and after the hurricane in order to understand the nature of their work before and after the storm, how the hurricane affected their work, as well as to tell the stories of those who had not been prominent in national media accounts overall. In particular, we sought to hear the voices of the midlevel student affairs administrator, as these individuals are most often those with the greatest responsibility for coordinating and implementing programs and policies on their campuses (Mills, 2000). Midlevel student affairs administrators are also those who generally have more extensive contact with students (Mills, 2000), whereas chief student affairs officers (CSAOs) may have less day-to-day contact with students (Ambler, 2000). These midlevel student affairs administrators, therefore, were those who we were interested in hearing from in regard to their role in the hurricane and their relationships with students.

Student affairs administration, originally designed to support the academic mission of the university (Nuss, 2001), typically encompasses those services directly related to students' needs both inside and outside of the classroom. Nuss describes the nature of the student affairs profession as one with a "consistent and persistent emphasis on and commitment to the development of the whole person" (p. 23). We differentiate the work described by Nuss as that belonging to student affairs as opposed to work conducted traditionally within the classroom by faculty members as that of academic affairs. The administrators we interviewed represented myriad aspects of student affairs, from those serving in residence life and housing to those working within student activities, Greek affairs, career services, and international student affairs. Each of these accounts reinforced Nuss's defini- 
tion of student affairs' work emphasizing student affairs' importance to students at their institutions as well as student affairs' support of the overall mission of the universities they served.

Furthermore, we sought to interview student affairs administrators from the multiple institutional contexts existent in New Orleans, Louisiana. While other cities and other institutions were hard hit by Hurricanes Katrina and Rita, New Orleans sustained catastrophic damage, affecting all of its institutions of higher education as the city virtually shut down for months. New Orleans is home to a large percentage of Louisiana's 90 total institutions of higher education, including public and private, religious and secular, community colleges and professional schools, as well as historically Black and predominately White institutions (The Chronicle of Higher Education, 2005). New Orleans, itself, is a city rich in culture and history. Indeed, its unique history and diverse culture greatly influenced the development of the higher education system as it exists today, whether it be through the emergence of several historically Black institutions, its diverse community college system, or its representation of public and private colleges and universities. These institutions have historically served the multitude of populations of New Orleans and the State of Louisiana in addition to responding to Louisiana's unique political and historical changes throughout time (Fairclough, 1995).

Each of the institution's particular contexts and missions "influence[s] all aspects of the day-to-day institutional life" (Barr, 2000, p. 25) including how the institution is governed, how decisions are made related to the institution, how resources are allocated, and which programs are created and developed (Barr, 2000). Taken together, an institution's mission and context combine to create institutional culture. Kuh and Whitt (1988) define culture in higher education as:

The collective, mutually shaping patterns of norms, values, practices, beliefs, and assumptions that guide the behavior of individuals and groups in an institute of higher education and provide a frame of reference within which to interpret the meaning of events and actions on and off campus (pp. 10-11).

For example, the culture at a large, public, research institution is largely different from the culture found at a small, religiously affiliated, pri- 
vate, liberal arts institution. The distinct culture of each institution therefore greatly influences what Nuss (2001) referred to as the dayto-day practices, policies, and procedures of the institution and its constituents. These cultures also influence how decisions are made within the larger organization. Birnbaum (1988) discussed these institutional cultures as organizational frames, representing different sizes and organizational structures among institutions.

The role of student affairs within each individual institutional culture varies as well. Whereas student affairs administrators at large, public institutions may have highly defined and structured job descriptions with clear reporting lines and power structures, administrators at smaller institutions may have more general job descriptions that involve multiple roles within the larger student affairs context (Miller, 2000). Furthermore, the decision-making structures at each institution greatly influence the role student affairs plays in overall institutional governance. For example, one institution may position a CSAO within the president's or chancellor's cabinet, while another may combine the administration of student affairs with other administrative units of the institution such as academic affairs (Ambler, 2000).

Finally, an institution's culture plays a significant role in how student affairs is viewed within the larger institution. It is common knowledge that academia often undervalue student affairs' work. This lesser status is often reflected in a marked tension between student affairs and faculty members, a tension described by Engstrom and Tinto (2000) as one characterized by "misunderstanding, mistrust, disrespect, conflict, disdain, and antagonism" (p. 428). Although many student affairs administrators and the students with whom they work see the benefits of student affairs' work, a chasm persists at many institutions between what has traditionally been referred to as academic affairs and student affairs itself. Institutional culture, therefore, plays a significant role in the structure, function, and perception of student affairs' work. Within this study, we examined how student affairs work was influenced by Hurricane Katrina in New Orleans within five distinct institutional cultures. In total, we interviewed 15 student affairs administrators from five institutions of higher education, representing both public and private, religious and secular, as well as historically Black and predominately White contexts. What follows here is an outline of our methods to conduct this study, the themes that emerged from the 
interviews with our participants, and our interpretation of these findings through the lens of context and culture in higher education.

\section{Methods}

The guiding research question of this qualitative study asked, "How did Hurricane Katrina affect the work of student affairs administrators in New Orleans?" As previously stated, we chose the context of New Orleans, Louisiana, as it was the most dramatically devastated by the hurricane that hit on August 29, 2005 and by the ensuing damage resulting from the levee breaks throughout the city. In order to best understand the dimensions of our research question, we sought out administrators representing not only multiple positions within student affairs, but also at multiple institutions. New Orleans is home to multiple types of institutions of higher education including proprietary schools, online institutions, community and technical colleges, private and public institutions, and religiously affiliated and secular institutions. We chose five of these institutions, including two public and three private universities. These five institutions also represent diversity amongst themselves, as two of these institutions are generally regarded as historically Black colleges and universities, and two of these institutions are religiously affiliated. We have chosen not to explicitly identify the institutions included in this study nor the participants. We realize, however, that due to the rather intimate nature of higher education in New Orleans and the relatively small number of institutions represented that complete confidentiality is difficult. To the protect the identity of the participants as much as possible, we assigned pseudonyms to the participants, identified only general program areas in which they work, and labeled their workplace as only public or private.

Fifteen student affairs administrators constituted the participants for the study. We contacted participants after contacting the CSAO at each institution by e-mail in order to solicit their cooperation to conduct the study and to elicit participation from those student affairs administrators who had been present both before and after the storm. While two of these administrators recommended specific names of individuals to be contacted, two others sent out e-mails to their entire student affairs staff asking that they respond to our request for participation. 
One institution's CSAO did not respond to the initial e-mail so participants from this institution were contacted individually through e-mail for participation in the study.

Again, we were intentional in choosing to interview only midlevel student affairs administrators. These individuals play "a vital role in the student affairs function on the campuses of institutions of higher education" and are those who "frequently have significant responsibilities, but may not have final authority. They implement policy, but may not always feel an integral part of the decision-making process" (Mills, 2000, p. 135). While they bore a significant amount of responsibility, these individuals' voices were often unheard in accounts of the hurricane.

We sought diversity of participants by institution as well as by student affairs area in order to better understand the dimensions of student affairs work within and across institutions. We also desired diversity by race and gender among our participants, which resulted in a total of 10 women and five men, six African American and nine Caucasian participants. A breakdown of participants is included in Table 1.

After we obtained each participant's consent to participate, interviews were conducted. Interviews lasted from 45 to 90 minutes and were guided by a semistructured protocol in which we asked about the nature of the individual's work before and after the storm (see Appendix). While the protocol was structured in order to have comparable responses from which to conduct the analysis, the nature of the interview and the protocol itself allowed for participants to provide additional responses or themes that had not been predetermined. Twelve of the 15 interviews were conducted face-to-face in the offices of the individuals, with the remaining three conducted over the phone. Although no follow-up interviews were conducted per se, contact was made with several administrators following the interviews to clarify information provided and to request additional information as needed. All interviews were transcribed verbatim and analyzed using the constant comparative method.

The constant comparative method is described as "a research design for multidata sources, which is like analytic induction in that the formal analysis begins early in the study and is nearly completed by the 
Table 1

Participants by Pseudonym, Sex, Race, Institutional Status, and Student Affairs Area

\begin{tabular}{lllll} 
Name & Sex & Race & Institution & Area \\
\hline Monica & Female & African American & Private & Student Life \\
Paula & Female & African American & Public & International Student \\
Kate & Female & Caucasian & Public & Greek Life \\
Vaughn & Male & Caucasian & Private & Housing \\
Emily & Female & Caucasian & Private & Residence Life \\
Margaret & Female & Caucasian & Private & Campus Recreation \\
James & Male & African American & Public & Director of Career Services \\
Jill & Female & Caucasian & Public & Disability Services \\
Sydney & Female & Caucasian & Private & Orientation \\
Lydia & Female & African American & Public & Student Activities \\
Michael & Male & African American & Private & Student Activities \\
Charles & Male & Caucasian & Private & Student Activities \\
Nancy & Female & Caucasian & Private & Career Services \\
Anne & Female & Caucasian & Private & Orientation \\
Robert & Male & African American & Private & Campus Security \\
\hline
\end{tabular}

end of data collection" (Bogdan \& Biklen, 2003, p. 66). The steps of the constant comparative method, according to Glaser (1978), include (1) collect data, which we did through the interviews conducted; (2) find key issues, events, or activities in the data that become main categories for focus, which occurred through recurrent discussions as the interviews processed; (3) collect data that provide many incidents of the categories of focus, which was reached through the multiple interviews conducted at the different sites; (4) write about the categories explored, keeping in mind past incidents while searching for new, which again occurred throughout the multiple interviews; (5) work with the data and emerging model to discover relationships, 
which we accomplished throughout the interviews as well as during a lengthy session at the end of data collection to compare and contrast findings; and (6) sample, code, and write with the core categories in mind, which is represented through the presentation of the findings in this paper. The steps of the constant comparative method occurred simultaneously during our data collection until our categories were saturated and the writing began. The use of Glaser's steps in data analysis allowed for emergent themes to develop from the data and provided a means by which large amounts of data were compressed into meaningful units for analysis. We obtained trustworthiness through the ongoing discussions and comparisons of data by the six researchers conducting the study as well as through follow-up with several participants in the study. Researcher bias was discussed prior to conducting the study including the proximity of New Orleans and the disaster to the researchers' own personal lives, as several of the researchers hailed originally from Louisiana. Furthermore, as several of the members of the research team were or had been student affairs administrators themselves, the potential bias occurring from this positionality was also discussed and evaluated prior to the study being conducted.

\section{Findings}

Four overall themes emerged from our analysis of the interviews: (a) decision making, (b) communication, (c) resources and limitations, and (d) student affairs status. These themes represent the nature of the administrators' work and how it changed due to the storm and the storm's aftereffects at these universities. These themes also reflect an analysis of how each institution's culture affected this change. It was evident that each and every one of the participants experienced dramatic changes in how they viewed their roles as student affairs administrators including new responsibilities, behaviors, attitudes, and perceptions. These changes in their roles were greatly affected by the scale and scope of the devastation that occurred at their particular institution and in their individual lives, as well as the institutional context and culture in which they were employed. We discuss in turn each of the four emergent themes followed by the conclusions and implications resulting from the analysis. 


\section{Decision Making}

In the immediate wake of Hurricane Katrina many citizens of Louisiana felt they had escaped the worst. While many evacuated the Gulf Coast areas and New Orleans, many others chose to stay. Many of the individuals who chose to remain in New Orleans believed that the hurricane would not cause dramatic damage, and in many ways they were correct. Indeed, it was not Hurricane Katrina itself that caused the inestimable damage to New Orleans but the collapse of weakened levees caused by the hurricane that finally brought the city to its knees. Robert, a campus security administrator, told us, "I actually rode out the hurricane sitting right here in this chair. After the hurricane passed, we walked outside and we assessed the damage. We had some water, but the campus was navigable by vehicle. We thought we would be okay." Then the levees broke. Robert said, "When the levees broke I knew we were in serious trouble. I knew that the campus would be covered in water and we would have to swim wherever we went. So, at that point, we went into survivor mode."

What came before and after the hurricane hit and then once again after the levees broke was a series of decisions for the administrators at these New Orleans' institutions. What our participants' interviews illustrated were the great differences in what these decisions were, how they were made, and the lingering effects of those decisions to this day. In Robert's case, he worked collaboratively with other administrators to make the necessary decisions to survive and evacuate the students from New Orleans. However, other individuals, like Lydia, were not included in the initial decisions before and immediately following the storm. She remarked, "I was not involved. It was the [chief university administrators]; they pretty much made the decisions about what was going on." Each institution's student affairs administrators had varying degrees of involvement in the initial decisions made, including the decision to evacuate prior to the hurricane or how to deal with the damage and devastation following it. What was clear, however, was the influence of institutional culture upon how and by whom these decisions were made.

\section{Public Versus Private}

It is perhaps not surprising that great differences emerged in the decision-making structures by type of institution. Birnbaum (1988) dis- 
cussed these differences in institutional type in terms of models of organizational functioning, thinking of the smaller institutions often as collegial institutions, or those that tend to share power and values in what they consider to be a "community of equals" (p. 85), and the larger institutions as political or anarchical institutions, wherein the administration acts as autocrats within the larger institution, trying to make sense of what is often a chaotic system. We found similar distinctions in decision making by institutional type. While certainly not all private institutions are small nor are all public institutions large, in Louisiana, these stereotypes seem to ring true. The smaller institutions in our study were private institutions with relatively flat organizational hierarchies, and the two public institutions were parts of large stategoverned systems that had elaborate hierarchies and power structures within each institution.

The differences in decision making came across in the participants' descriptions of what happened immediately following the catastrophic events in New Orleans. For example, administrators of private institutions, like Robert, talked of making collaborative decisions with other administrators. Likewise, Jill, another private institution administrator, talked of the collaborative decision making that occurred as a result of the close quarters of the remote operation center for the administration. She said, "I think it was kind of coalition-building. You know, people you may have e-mailed with or spoken with on the phone, you are now sitting next to that person, sometimes on a daily basis. So it became a different dynamic, and I think it helped facilitate a lot of the relationships at the university."

However, administrators at public institutions, like Kate, remarked about the decision making that occurred outside her department and decisions that came from upper administration. She commented, "We were just sort of told to hold tight and they would let us know when to do anything and it was probably about the second or third week in September, I would say, when we started getting messages about how everything was going to work." When asked about the decision making that occurred at her public institution after the storm, Lydia laughed and said, "I don't know if I can say anything good about that. I don't think I could say anything good about it that you wouldn't bleep out." Indeed, the administrators at the private institutions in our study had many more positive comments about the decision making 
that occurred prior to and directly after the storm as opposed to their public counterparts. Lydia, in particular, was very critical of the decisions that had occurred. She told us at length:

The things that have occurred could not have happened if somebody didn't approve it. Somebody gave permission for it to happen. Katrina, you had no control of, but the things like the cutting of programs, somebody had to give approval for that. The insensitive responses: "If you can't make it work then I suggest you find another job," that's insensitive. That's not Katrina, that's people in control who have stepped aside and said as long as I'm okay and me and mine are okay. ... And you can't run a university, you can't run an institution with leaders who are insensitive. And that's where we are. All the hidden things were revealed after Katrina, you couldn't hide it anymore; the insensitivity was revealed. I mean it was always there, but it just became so blatant after the storm.

Kate, another public institution administrator, had similar criticisms of how decisions were made after the storm:

I definitely have lost some confidence in the leaders of the university. The university as a whole seems to have become much more insular in that those who are making decisions tend to beat least the perception amongst those of us who are kind of in the trenches-is that there is not as much input gathered. It tends to have become much more of a centralized form of leadership than a democratic form. But I certainly think it's safe to say that I don't have nearly as much confidence as I used to.

This is not to say that all of the administrators at the private institutions were satisfied with the leadership shown by the institutional leaders during the crisis. Sydney, an administrator at a private institution, commented,

For me personally, it felt like you were doing as much as you possibly could under some pretty unusual circumstances and you were expected to do more. I mean, it was like, what else can you do? You felt you were giving just about all you could give and you didn't necessarily see the same from the leadership. 
When asked about the upper administration's decision making after the storm, Paula, an administrator at a public institution, similarly remarked, "You know, they did the best they could. How do you really prepare for something like this? Did I agree with every decision that they made? Not necessarily, but they had some tough decisions to make."

\section{Decision Making After the Storm}

The student affairs administrators also talked about the nature of how decisions were made during the crisis itself. Many discussed the need to make different types of decisions or changing leadership styles during a crisis in order to "do what needed to be done." However, as the above quotes illustrate, it was often the administrators at the private institutions who talked about changes in decision making as they tended to be those given the power to make decisions.

Emily, who worked at a private institution, had to evacuate with the students to a nearby state; and in a series of difficult days that ensued, she was charged with making many difficult decisions about how to handle the situation. She remarked, "You just have to go and you have to take charge and you have to do things because they need to be done. It's one of those sink-or-swim situations and, fortunately, I feel like I was able to swim in that situation." She continued, "It's one of those things when you just keep going. You don't think about it. You just keep moving and doing what you have to do." Sydney, another private institution administrator, commented similarly, "No one knew the protocol so you just did what you could, and whether it was right or it was wrong, there's no way to quantify. You just did it and you tried to figure out how to keep moving."

Regardless of who made the decisions, decision making was not easy. The circumstances that faced those, in particular, who were left with students who had not evacuated, were often life-threatening and most certainly beyond the scope of everyday decision making in student affairs. Charles, for example, talked about making decisions in terms of basic human needs, like those discussed in Maslow (1970): "food, shelter, and safety." Robert further explained the desperate situation many of these administrators were faced with: 
Small things became critical. I cut my hand and I didn't know we were getting rescued that day; it scared me to death. The possibility of infection, that I would lose this hand. It was a minor cut but we had no way to clean, we had no way to bandage it, so you know, survival mode is the best way I can describe it.

The majority of institutions of higher education have formed crisis plans in the past years, especially in light of events surrounding September 11 and other campus crises (e.g., Smith \& Millar, 2002). In the coastal regions typically affected by hurricanes, institutions have done no less. Nevertheless, the administrators all discussed the fact that no matter how much an institution might feel prepared in regard to a crisis, there can be no real preparation for a disaster of the magnitude faced by those in New Orleans. Vaughn, a private institution administrator, stated, "You're never prepared for any disaster, let alone what is being called the worst natural disaster we've ever faced. There's just nothing you can do to prepare for it. You never know what you're going to have to do to deal with or manage a situation." Charles, another private institution administrator, talked about how a different leadership style is needed in a crisis such as the one wrought on New Orleans after Katrina:

I think there are simply a lot of valuable lessons in changing the leadership style in the middle of a crisis. And being more adaptive, being more flexible, becomes important; resisting the urge to yell and scream at people around you who are trying to help. To know that everyone is working just as hard, that patience is going to be required more so now because everything is so crazy.

In the same vein, Charles talked about how his own personal leadership style changed:

During the storm, by virtue of necessity, I became much more of an autocrat with [statements like], "You are directed to do this and this is your deadline. This is what I need to get done and here's why-get it done." That type of thing instead of the normal, the softer approach of, "Don't you think it would be a good idea if we set up a student Web site where the students could communicate?" This was, "Now I want it done. Design me a web page and get it up there. Get it going. Tell your friends to join-make it happen." 


\section{Communication}

As a result of Hurricane Katrina, communication among administrators and between the institutions and their students were also greatly affected. At the smaller, more closely connected institutions, communication was vital to those who were separated from the university, their colleagues, and their students. Anne, an administrator from a private institution, remarked, "I think in general people were just very anxious to hear from one another, you know, even if it wasn't really anything of importance." Nancy, another private institution administrator, talked about what they did to communicate with one another following Katrina:

Once we realized that we could contact the students when the Web site came up, we started blogging. As administrators and faculty across the campus, we all started to get something up, either a blog or some type of community bulletin board so people were at least aware of, [and we could ask], "Is everybody okay? Who's been heard from and who has not? Are people still stuck in New Orleans?" We were very concerned. Then those who weren't checking in, we couldn't pick up the phone and call them. We still didn't have phone service. So it was very frustrating and very frightening.

Lydia, an administrator from a public institution, talked of the opposite nature of her institutional culture, a general feeling of being "left in the dark":

The first 4 days, I was a zombie. I didn't talk to anybody, I mean not work-related. So I think it was, I guess about the week, the following week-maybe 7 days, because the hurricane came that Monday and through that Friday I didn't hear from anybody. There wasn't an official word.

Kate, another public institution administrator, echoed Lydia's sentiment: "The faculty, the staff, the students, we were just all at a loss. We all wanted so much information, just like everyone in south Louisiana did at that time. We were just starved for any information and nobody could get it." Jill, also in a public institution, expressed her frustration at what she considered to be a lack of information from those making decisions: 
Communication of basic information I think could have been better, too. It could have been done in an e-mail or in some format like, "This is the state of affairs this week," even as far as what happened to the building in which you work. That information was never disseminated. We never received an e-mail saying exactly what damage happened on campus or how the flooding affected the campus. That wasn't information we were able to find out through the university, but kind of had to hunt down on your own. I found that pretty frustrating, you know, not knowing when I was able to return, what I was going to return to as far as resources, did it flood, was it destroyed; those kinds of things. I think little updates like that would have helped a lot of other people feel a little bit, you know, have one area of their life where they could feel a little bit more comfortable or competent or something.

Regardless of the institutional culture, all 15 of the administrators interviewed talked about their first priorities being locating and communicating with their students. In general, each of these administrators works with a specific group of students that they tend to know on a more personal level. Therefore, finding their students became paramount after the storm. What assisted both public and private institution administrators in finding their students was often the communications technology available to them. Vaughn explains how he found his students:

It was really exclusively by e-mail. [The students] developed these communities at these 596 schools [to which they evacuated] like you wouldn't believe, and they did it only because of the communication methods we have in place now in this day and age. You know, if this were 15 years ago, we would have never been able to find those 596 schools, ever. We would have never brought back as many students as brought back here in January had blogs, online communities, and online communications not been around; we wouldn't be here right now, period.

Margaret, another private institution administrator, told a similar story of technology and communication: 
Communication was such a huge issue because we had such poor communication initially. It was text messaging that we used, then we moved to a Facebook site and that became a great way for us to share information with our student employees and also Myspace. We had to think out of the box and use creative mediums to communicate.

Kate, a public institution administrator, also used technology to find her students: "I was able to track down the majority of our students. It took a couple of weeks going through stuff like Facebook and like one student's Hotmail account that I just happened to remember."

\section{Resources and Limitations}

Much like other aspects of public and private institutions, the resources available to these institutions and the limitations that they face are often quite different. In the wake of Hurricane Katrina, all of the institutions in New Orleans faced innumerable challenges to rebuild, recruit new students, and retain the already enrolled students. With diminishing student enrollment and expensive repairs awaiting them, resources were scarcer than ever. In addition, each of the institutions faced staff attrition, making a difficult situation even more difficult.

Specifically, private institutions faced multiple challenges by the diminished resources they faced upon returning to campus. While public institutions certainly faced large budgetary issues and the resulting diminished resources, private institutions and their administrators were often in more difficult situations. Since student affairs administrators at smaller institutions traditionally play multiple roles and represent multiple areas of responsibility (Miller, 2000), a shortage of staff and resources became even more dire. Nancy commented about the limitations facing her and her institution:

We are living in a very changed environment here. We've lost a lot of students, we've lost a lot of staff members, and faculty have been lost as well. There's been a lot of personal life issues converging on our work here and it makes it difficult for people to just keep right on plugging along. We are working under some pretty horrific circumstances in that, you know, I at this point am 
pretty much responsible for the work that is ordinarily done by three people.

Charles, at another private institution, echoed these concerns:

We have three professionals to do the job of six right now. We're critically short staffed, but the needs of the students don't change. Whether we have five [students] on campus or we've got 15,000, the services are the services that we provide and they have got to be provided.

Michael, also a private institution administrator, similarly quipped, "We had to fill dual roles ... dual roles suck."

Public institutions also faced cutbacks in staff and resources, often at higher levels than those of the private institutions we studied. James, a public institution administrator, told us, "We lost 40 percent of our students, we lost 40 percent of our staff, we lost 40 percent of our faculty; so we lost quite a few areas." At the public institutions, space also became a primary limitation. Many of the public institutions' campuses were almost entirely destroyed, which made program delivery nearly impossible. Lydia remarked, "Because we had limited space, we couldn't do anything. We have, I mean, no places for meetings, we have no places for large groups. No place really to just meet and just talk." Kate, had a similar remark, "Many of our buildings are still not fully functional and that's been a big hardship for some of our student organizations because they haven't had places to meet in that building [the union] that they've depended on so much." Jill summed up these dilemmas by saying, "There was this kind of chaos because people didn't have time and space and access to what they needed."

\section{Student Affairs' Status}

Our final theme came from our participants' comments regarding the overall perception of student affairs at their institutions. While each of our participants felt that the work they did before and after Katrina was instrumental to the institution's and their students' success, how this work was perceived by others was often viewed very differently. In many cases, these administrators felt their work made a dramatic difference in elevating student affairs' status on their campuses, lend- 
ing them and the profession more credence and respect. However, like the other themes emerging from our conversations with these administrators, their view of student affairs' status differed greatly by institutional type and culture.

Charles, at a private institution, remarked about the status of student affairs in general and how it changed after the storm:

Whether people want to admit it or not, student affairs is last, lowliest, and least, period. People don't really understand the importance because it is hard to measure. How do you measure community building? How do you measure the sense of connectedness to the institution? It's like the storm probably did a world of good. It washed away a lot of stuff and the sun is shining now and people go, "Oh, yeah, what we do is important. It's not just, you know, games out on the quad."

Michael, another private institution administrator, similarly commented, "I don't think we're justifying student affairs as much as we have in the past. I think a lot of universities have come to grips that we're a very important part of the university."

At the public institutions, the administrators' outlook differed from those of their private counterparts. Lydia remarked upon her frustration, saying, "Student affairs is the lapdog of the university. According to this administration, academics run the university." Kate similarly posited, "I wish we were a profession that garnered more respect from other people in higher education, and I think the storm just intensified my feelings about that at this university. I don't feel like student affairs is a big priority." Jill, an administrator at a public institution, and Monica, an administrator at a private institution, were the exceptions, however. Jill felt that the work she and her colleagues had done had greatly improved student affairs status at her institution. She stated:

Student affairs has never been a high-priority area for the university and what happened was that there was a shift. There was a huge push in our area and in the division of student affairs to make sure there was enough programming and planning of events for students to compensate for the lack of resources and the community at large. So I do think that that provided that shift, that 
emphasis to kind of say, "Hey, these people really do know what the heck they're doing and they really are important to the university." I think we've notched ourselves up a little bit, which is a pretty good thing.

Whereas Monica, from a private institution, felt the opposite:

I just really felt like people needed to be reminded that people in student affairs had degrees, and that we're not just sitting in our office trying to figure out how to plan a spades tournament. I think it's time, and definitely post-Katrina we see that, but I think it's time to really demand a level of recognition and respect that may not have been there pre-Katrina. I mean, pre-Katrina it may not have been as visible, but now it's glaring.

\section{Conclusions}

The goal of this study was to give voice to those who had not been heard-to hear the voices of the people "who stayed," the people "in the trenches," and the people who "are dedicated to the students, no matter what." While much of the media covered the views of top administrators, faculty, and occasionally students, there has not yet been any attention given to whom we consider to be the unsung heroes of Hurricane Katrina at New Orleans' institutions of higher education. In this exploratory study of 15 administrators' experiences at five institutions of higher education, we found these heroes and attempted to tell their stories. What was interesting in these stories was the role that institutional culture and context played in what occurred before and after Hurricane Katrina and that continues to play a role in their status today.

The private institutions in this study generally experienced less hierarchical organizational structures than their public counterparts, however the private institutions' dependence upon a few individuals for multiple responsibilities resulted in more stressful workloads for these individuals following the hurricane. While it can be said that the large amount of attrition following the hurricane affected all student affairs administrators' workloads and responsibilities, the circumstances following the hurricane only exacerbated the already overburdened workload of the administrators at the private institutions. Additionally, 
the extreme hierarchical nature of the public institutions left these student affairs administrators disenfranchised from the decision making that occurred before and after the storm. The culture of the public institutions we studied also generated some negativity from the administrators interviewed due to their often marginalized status. While all of the participants saw their importance in the lives of the students with whom they work, they did not tend to feel that their work and their efforts were recognized by the larger institutional communities in which they work. Again, administrators at the private institutions were more likely to see their status rise at their institutions post-Katrina, but it will be interesting to see if these opinions remain intact as processes return to "normal" on their campuses.

We acknowledge the limitations faced by this study. For example, we interviewed a few participants from only five institutions, and these individuals are only representative of midlevel student affairs administrators. Furthermore, we included an unequal amount of public and private institutions in our participant base. Due to the status of the institutions in New Orleans, we were unable to interview participants from all of the damaged institutions, as many of them had not yet obtained stable communications or organizational structures during the time of our study. Finally, we were aware that unequal demographic characteristics of our participants, including race and gender, could be major limitations to this study. Certainly, future studies must seek to explore all facets of institutional and administrative identities in understanding how decisions were made and how they were affected by individual characteristics. Nevertheless, we believe that this exploratory study lends itself to improving the further study of student affairs and the effects of crises at institutions of higher education throughout the United States. Asking questions about the influence of race, gender, marital status, and the status of particular student affairs areas over others would all form important studies in order to better understand the confluence of individual and institutional characteristics upon decision making during crises.

Finally, this study contributes to the overall literature about student affairs administrators and crisis management in higher education. Understanding one's institutional context and culture are important to the decisions made during a crisis and how these decisions are communicated to one's constituents. Further, acknowledging the expertise 
of student affairs administrators and their close relationships with students are important to maintaining balance after a crisis occurs and in reaching out to the students who need their help. These individuals "do what needs to be done" on a daily basis; and in many cases during Hurricane Katrina, they went above and beyond their duties to make a difference at their institutions and to save the lives and spirit of their students, faculty, staff, and communities.

\section{Appendix}

\section{Hurricane Katrina \& Student Affairs in New Orleans Protocol}

\section{Background Information:}

1. Job title - official - general

2. How many people report to you? Who are they?

3. Who do you report to?

4. How long have you been in this field?

5. How long have you been at this institution?

6. Did you work in any other professions before this? If so, what were they and how long were you employed in them?

7. Educational background

a. Any student affairs specific coursework/degrees/professional development?

8. Could you tell me your age, race, and gender?

Now we're going to transition to talking about how the hurricane affected your work, your work with students, your professional identity, leadership approach, and priorities before, during, and after the hurricane.

1. Let's begin by talking about the nature of your work in student affairs (e.g., administrative duties, interactions with others, at divisional level and at institutional level).

a. What was it like before the hurricane?

b. How about when the hurricane hit?

c. How has it changed since the hurricane? 
2. How about your interaction with students as a professional?
a. Before?
b. When the hurricane hit?
c. After?

3. Thinking about your leadership style in terms of decision making and communication with others, how did the hurricane impact your approach to leadership ...
a. In regard to those who report to you?
b. In regard to your peers?
c. In regard to those whom you report?

4. What would you describe as your priorities before the hurricane? Why?
a. During? Why?
b. After? Why?

5. What was your view of the student affairs profession before the hurricane, and do you think it has changed and how?

6. What didn't I ask you about your experience that you would like to share?

\section{References}

Ambler, D. A. (2000). Organizational and administrative models. In M. J. Barr, M. K. Desler \& Associates (Eds.), The handbook of student affairs administration (pp. 121-134). San Francisco: JosseyBass.

Barr, M. J. (2000). The importance of institutional mission. In M. J. Barr \& M. K. Desler (Eds.), The handbook of student affairs administration (2nd ed., pp. 25-49). San Francisco: Jossey-Bass.

Birnbaum, R. (1988). How colleges work: The cybernetics of academic organization and leadership. San Francisco: Jossey-Bass.

Bogdan, R. C., \& Biklen, S. K. (2003). Qualitative research for education: An introduction to theories and methods. Boston: Allyn and Bacon.

Cowen, S. S., \& Wildes, K. W. (2006, April 21). After Katrina: Two presidents reflect. The Chronicle of Higher Education, pp. B12-B14. 
Engstrom, C. M., \& Tinto, V. (2000). Developing partnerships with academic affairs to enhance student learning. In M. J. Barr $\&$ M. K. Desler (Eds.), The handbook of student affairs administration (2nd ed., pp. 425-452). San Francisco: Jossey-Bass.

Fairclough, A. (1995). Race and democracy: The Civil Rights struggle in Louisiana, 1915-1972. Athens, GA: University of Georgia Press.

Glaser, B. (1978). Theoretical sensitivity: Advances in the methodology of grounded theory. Mill Valley, CA: Sociology Press.

Hoover, E. (2005, September 16). A beloved black university fights to survive. The Chronicle of Higher Education, p. A21.

Kuh, G. D., \& Whitt, E. J. (1988). The invisible tapestry: Culture in American colleges and universities. Washington, DC: The George Washington University.

Mangan, K. S. (2005, September 9). Hurricane devastates campuses on Gulf Coast. The Chronicle of Higher Education, pp. A1, A28-A29.

Maslow, A. H. (1970). Motivation and personality (2nd ed.). New York: Harper and Row.

Miller, T. E. (2000). Institutional governance and the role of student affairs. In M. J. Barr \& M. K. Desler (Eds.), The handbook of student affairs administration (2nd ed., pp. 37-49). San Francisco: JosseyBass.

Mills, D. B. (2000). The role of the middle manager. In M. J. Barr, M. K. Desler \& Associates (Eds.), The handbook of student affairs administration (pp. 135-153). San Francisco: Jossey-Bass.

Nuss, E. M. (2001). The development of student affairs. In S. R. Komives \& D. B. Woodard, Jr. (Eds.), Student services: A handbook for the profession (3rd ed., pp. 22-42). San Francisco: Jossey-Bass.

Selingo, J. (2005, September 16). Putting a university back together. The Chronicle of Higher Education, p. Al8.

Selingo, J. (2006, May 26). Tulane U. sets the pace for recovery. The Chronicle of Higher Education, pp. A30-A32.

Smith, L. L., \& Millar, D. P. (2002). Before crisis hits: Building a strategic crisis plan. Washington, DC: American Association of Community Colleges.

The Chronicle of Higher Education. (2005). Almanac issue 2005-2006. The Chronicle of Higher Education. 